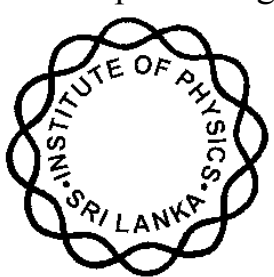

INSTITUTE OF PHYSICS - SRI LANKA

Research Article

\title{
Effects of acidification of clove fruit dye extracted in water and ethanol for performance enhancement of DSSCs
}

\author{
D.T.B. Herath ${ }^{1 *}$, G.C. Wickramasinghe ${ }^{2}$, G.M.L.P. Aponsu ${ }^{1}$ and V.P.S. Perera ${ }^{2}$ \\ 1. Department of Physical Sciences and Technology, Sabaragamuwa University of Sri \\ Lanka, Belihuloya. \\ 2. Department of Physics, The Open University of Sri Lanka, Nawala, Nugegoda.
}

\begin{abstract}
Dye extracted from flesh of Clove fruit (Syzgium aromaticum) was used as the sensitizer in Dye Sensitized Solar Cells (DSSCs) of the configuration $\mathrm{TiO}_{2} /$ dye/electrolyte/Pt. Pigments of Clove fruit was extracted by soaking in distilled water and ethanol and again boiling in both the solutions. Since DSSCs made using dye extraction in ethanol produced higher efficiency than in water, glacial acetic acid was added to dye extractions in ethanol at different ratios to examine any further enhancements. The Clove fruit extract absorbed appreciable solar radiation in the wavelength range 500 - $700 \mathrm{~nm}$ that makes it suitable for a DSSC. FTIR spectra of the dye extracts revealed the hydroxyl groups attached to dye is prominent after acidification with acetic acid that helps to anchor on $\mathrm{TiO}_{2}$ surface.

DSSC fabricated using mixture of fruit dye in ethanol and glacial acetic with the ratio of 1:3 produced the highest efficiency of $0.69 \%$ with the photo current of $2.50 \mathrm{mAcm}^{-2}$ and fill factor of $61.57 \%$. The electron life time calculated from bode phase plots of the cells also supported the above observations. The enhancement with acetic acid treatment of dye is attributed to intensification of absorption of visible light and strong coupling of the dye with $\mathrm{TiO}_{2}$ due to the presence of anchoring groups in acidic form is evidence from UV visible and FTIR spectroscopy.
\end{abstract}

Keywords: Clove fruit, Dye sensitized solar cells, acetic acid treatment

* Corresponding author: 22232dimuth@gmail.com 


\section{INTRODUCTION}

Currently available solar cells compose of single-crystalline, polycrystalline and amorphous forms of inorganic and organic materials. Foremost popular solar cells are made of silicon and their success is due to moderate efficiency and durability relative to organic solar cells. Dye Sensitized Solar Cell (DSSC) is a kind of solar cell with both organic and inorganic hybrid. The manufacturing cost of DSSC is however, lower than that of silicon based solar cells. A DSSC is a device fabricated using a high-band gap semiconductor to transform light into electrical energy by sensitization of an organic dye [1]. Due to the advantage of lower production costs and simple and easy development process, DSSCs are of considerable concern. They can be assembled at room temperature in normal environments, and their cost is just about $1 / 10^{\text {th }}$ of the conventional solar cell. This study was intended to investigate the performance of DSSC sensitized with a dye extracted from Clove fruit into water and alcohol and also to examine the performance of DSSCs by acidification of those extracts with acetic acid.

\section{METHODOLOGY}

\subsection{Preparation of dye solutions}

$30 \mathrm{~g}$ of Clove (Syzygium aromaticum) fruit fresh was ground in an electric blender and dye was extracted by soaking in $100 \mathrm{ml}$ of distilled water and ethanol for 10 minutes. Dye was also extracted by boiling aforementioned bend in distilled water and alcohol at $100{ }^{\circ} \mathrm{C}$ and $80{ }^{\circ} \mathrm{C}$ respectively for 10 minutes. Dye solutions were separated by filtration and the filtrates were stored in a dark coloured bottle in a refrigerator until use.

\subsection{Preparation of $\mathrm{TiO}_{2}$ films}

Fluorine-doped Tin Oxides (FTO) plates were cut into the size of $1 \mathrm{~cm} \times 2 \mathrm{~cm}$. The glass plates were cleaned respectively with tap water, detergent and distilled water by using ultrasonic cleaner for 5 minutes in each case. Washed glass plates were boiled in ethanol, in a beaker on a hot plate at $80{ }^{\circ} \mathrm{C}$ for 15 minutes. $0.5 \mathrm{~g}$ of P25 Degussa Titanium dioxide $\left(\mathrm{TiO}_{2}\right)$ powder was mixed with $0.1 \mathrm{~g}$ of citric acid in a mortar using a pestle with $7 \mathrm{ml}$ ethanol, one drop of triton-X-100 and one drop of PEG-400. The mixture was ground for 15 minutes to obtain a uniform paste. The prepared $\mathrm{TiO}_{2}$ paste was coated on cleaned FTO glass plates by using the doctor blade technique and the area of the $\mathrm{TiO}_{2}$ films on FTO was $1 \mathrm{~cm}^{2}$. Finally, the $\mathrm{TiO}_{2}$ plates were heated in a furnace at $450{ }^{\circ} \mathrm{C}$ for 60 minutes. 


\subsection{Preparation of dye coated photo-anodes}

Dye solutions of $2 \mathrm{ml}$ that extracted by soaking Clove fruit in distilled water and alcohol and also boiling in those two solvents were taken into four test tubes. Another $2 \mathrm{ml}$ set of solutions were prepared by adding previously extracted dye in ethanol with glacial acetic acid at different ratios according to volume ratios of 3:1, 2:1, 1:1, 1:2, 1:3, 1:4, 1:5.

Afterwards $\mathrm{TiO}_{2}$ films on FTO glass were soaked separately in above dye solutions. Each sample was dipped in the dye solutions for 30 minutes and washed with distilled water or alcohol accordingly. Afterwards $\mathrm{TiO}_{2}$ films were dried carefully using a hair drier.

\subsection{Assembling of the DSSC and characterization}

The conducting side of the platinum counter electrode and dye absorbed $\mathrm{TiO}_{2}$ film were sandwiched and held with clamps. The capillary space between two electrodes was filled with an electrolyte which was prepared by using $0.83 \mathrm{~g}$ of potassium iodide (KI) and 0.127 $\mathrm{g}$ of iodine $\left(\mathrm{I}_{2}\right)$ added into a solution containing acetonitrile and ethylene carbonate at 8:2 ratio. After that the assembled cells were characterized for photovoltaic measurements under the irradiance of $1000 \mathrm{Wm}^{-2}$ illumination using a computer coupled galvanostat/potentiostat and ScienceWorkshop 750 Interface. UV-Visible spectra of extractions and acidified dyes were measured by using Multiskan Sky Microplate Spectrophotometer for optical characterizations. Infrared spectra of dye samples were obtained by using Bruker Tensor 27 FTIR spectrometer. Electrochemical Impedance Spectroscopy (IES) was measured by using galvanostat/potentiostat Metrohm Autolab PGSTA T204. Impedance measurements were performed at frequency range of $100 \mathrm{mHz}$ to $100 \mathrm{kHz}$.

\section{RESULTS AND DISCUSSION}

\subsection{UV Visible spectra of Dyes}

The absorption peak can be explained by the chemical structure and color of the dye. Physically, it can be explained by the difference between energy levels of the materials. Generally, all the dyes cannot be used for DSSCs, nevertheless they need to matches with the bands of the semiconductor to produce photocurrent when illuminated. Figure1. (I) shows the absorption spectrums of the extracts of Clove fruit flesh which was soaked in distilled water and ethanol and also boiled in the two solvents. 

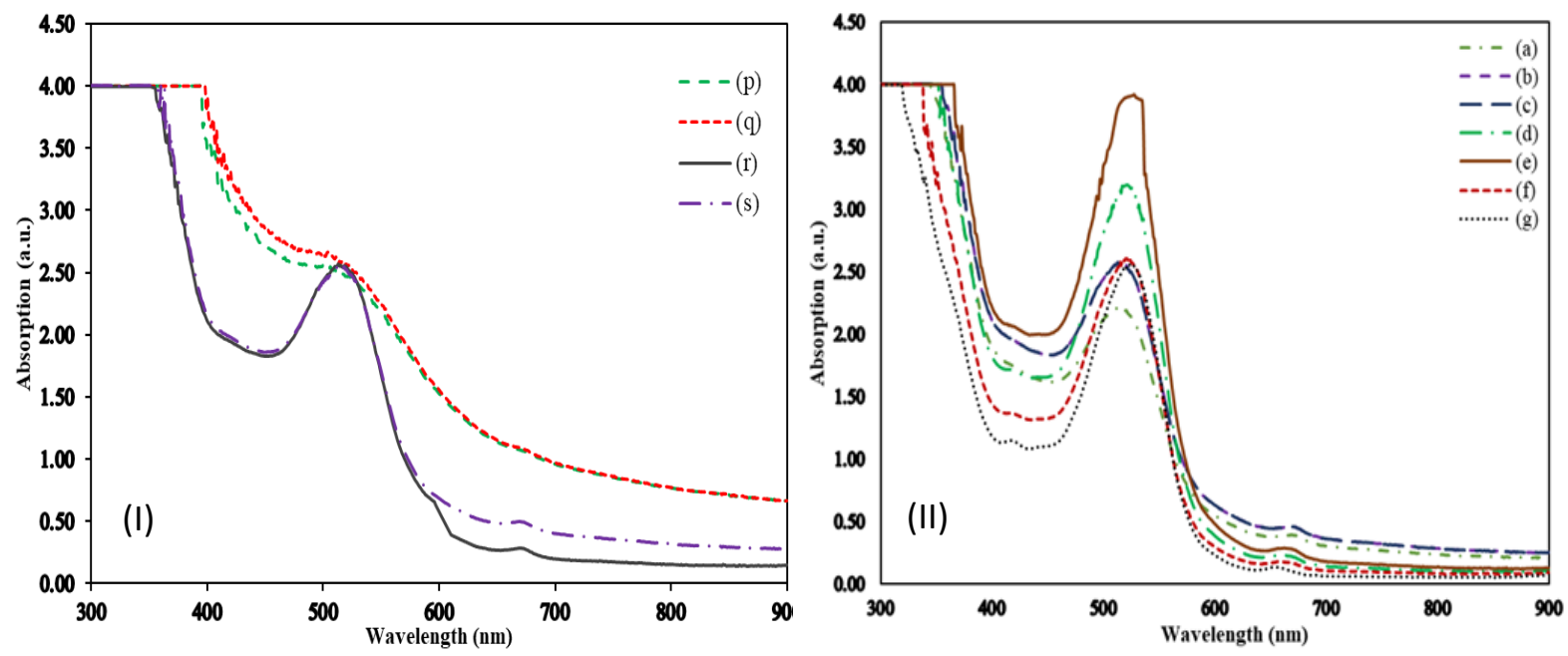

Figure 01: (I) Absorption spectra of clove fruit dye extracted in different solvents. (p) Distilled water (q) Distilled water $\left(100{ }^{\circ} \mathrm{C}\right)(\mathrm{r})$ Ethanol (s) Ethanol $\left(80{ }^{0} \mathrm{C}\right)$. (II) Absorption spectra of different volume ratios of dye in ethanol and acetic acid mixtures. (a) 3:1 (b) 2:1 (c) $1: 1$ (d) $1: 2$ (e) $1: 3$ (f) $1: 4$ (g) $1: 5$

All of the dye samples have absorption peaks in the visible region between $400 \mathrm{~nm}$ and 800 $\mathrm{nm}$, which could be an advantage because intensity of the solar radiation is maximum in the visible region. Figure 01. (I) revels that four different samples of dyes have peaks between $510 \mathrm{~nm}-520 \mathrm{~nm}$ and $670 \mathrm{~nm}-680 \mathrm{~nm}$. Two absorption peaks were obtained at $517 \mathrm{~nm}$ and $671 \mathrm{~nm}$ for the dye in ethanol and absorption spectrum of extracted dye in ethanol $\left(80{ }^{\circ} \mathrm{C}\right)$ have a hump at $572 \mathrm{~nm}$.

Figure 01. (II) illustrates the absorption spectra of samples with different volume ratios of dye and acetic acid. Most of the sample mixtures have peaks between $510 \mathrm{~nm}$ to $520 \mathrm{~nm}$ and $650 \mathrm{~nm}$ to $700 \mathrm{~nm}$. According to the graph, mixture (e) which is with the ratio 1:3 of dye and acetic acid got the highest absorption peak at $520 \mathrm{~nm}$. The mixture ratio of dye to acetic acid of 3:1 has the lowest absorption peak at $516 \mathrm{~nm}$. According to the literature [2]. Clove fruit dye contain flavonoid. Anthocyanin is considered as one of the flavonoids and following reaction is responsible for intensification of the absorption peak between $510 \mathrm{~nm}$ and $520 \mathrm{~nm}$ after acidification. 
(a)

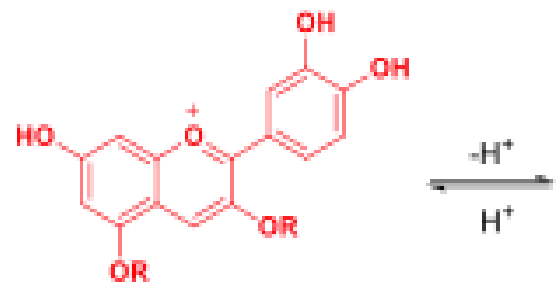

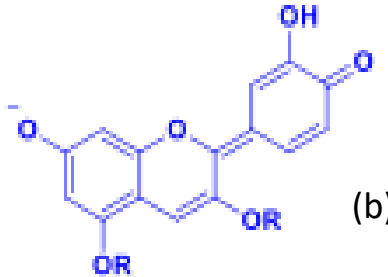

(b)

$\mathrm{R}=\mathrm{H}$ andior glycosyl substituents

Figure 02: Chemical structure of anthocyanin in (a) Acidic form (b) Basic form

\subsection{FTIR Characterization of Dyes}

Figure 03 displays the FTIR absorption spectra of the dye derived from the fruit of the Clove which is extracted to distilled water and ethanol. FTIR spectra of the natural pigment in the dye extraction were reported in the range $1000 \mathrm{~cm}^{-1}$ to $3500 \mathrm{~cm}^{-1}$. For the wide variety of hydrogen bonding, broad absorption in the range from $3000 \mathrm{~cm}^{-1}$ to $3500 \mathrm{~cm}^{-1}$ appears and band at $3332.68 \mathrm{~cm}^{-1}$ and $3316.07 \mathrm{~cm}^{-1}$ is due to the-OH stretching. The peak of at $1045 \mathrm{~cm}^{-}$ ${ }^{1}$ shows that $\mathrm{C}-\mathrm{O}-\mathrm{C}$ bonds are present. Therefore, in the dye extraction of Clove fruit, hydroxyl groups of pigment molecules can contribute to anchor the dye to the $\mathrm{TiO}_{2}$ photo anode.
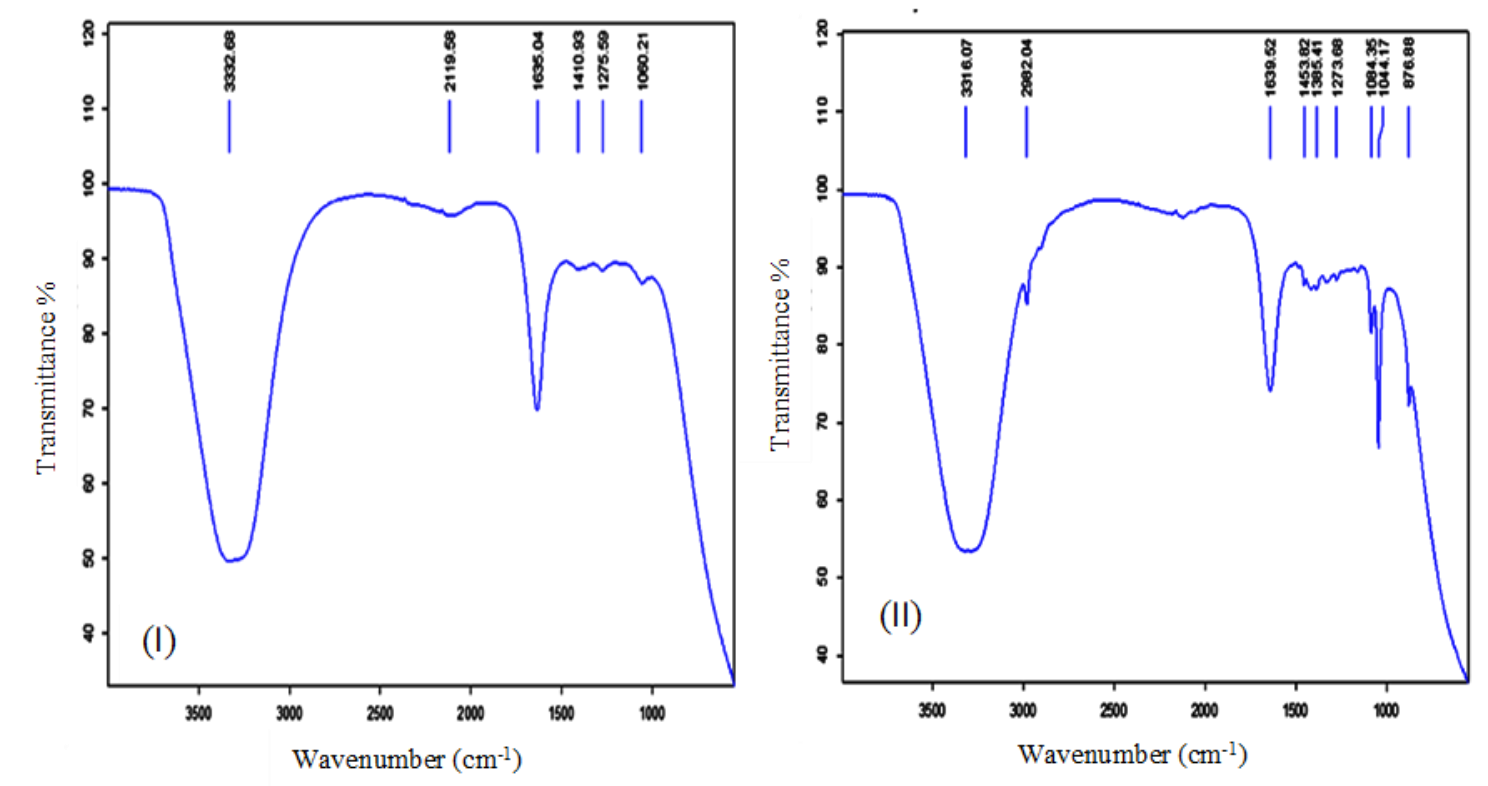

Figure 03: FTIR Spectra of Clove fruit dye extracted into (I) water (II) ethanol 


\subsection{J-V Characterization of DSSCs}

Figure 04. (I) shows the current density (J) and voltage (V) characteristics of DSSCs fabricated using $\mathrm{TiO}_{2}$ photoanodes coated with four different dye samples of clove fruit which are extracted by soaking in distilled water, boiling in distilled water at $100{ }^{\circ} \mathrm{C}$, soaking in ethanol and boiling in ethanol at $80{ }^{\circ} \mathrm{C}$. The short circuit current density of dye extracted by soaking in distilled water was the lowest. According to J-V characteristics plot of dye samples which are extracted by boiling in ethanol and soaking in ethanol were merely seen the same. Their short circuit current density and open circuit voltages were relatively higher than dye samples which were extracted in distilled water.
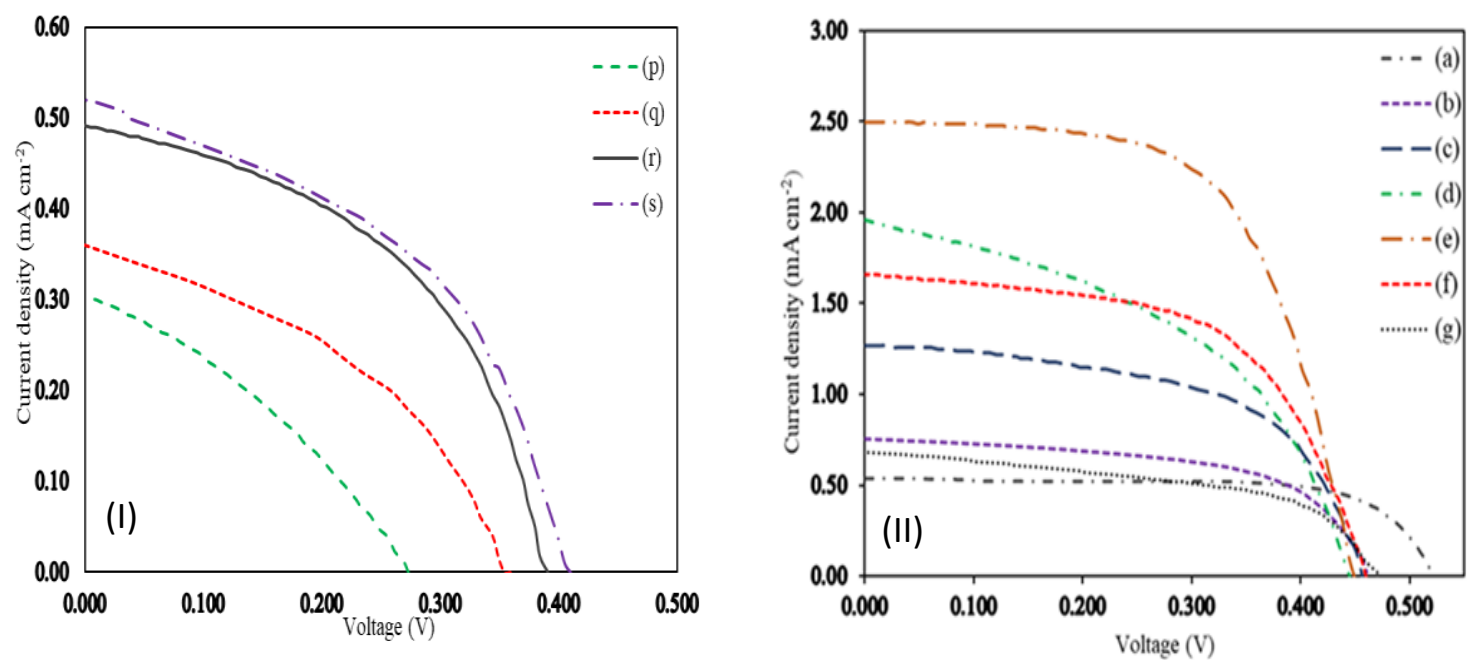

Figure 04. (I) J-V characteristics of DSSCs prepared using clove fruit dye in different solvents. (p) Distilled water (q) Distilled water $\left(100{ }^{\circ} \mathrm{C}\right)(\mathrm{r})$ Ethanol (s) Ethanol $\left(80{ }^{0} \mathrm{C}\right)$. (II) $\mathrm{J}-\mathrm{V}$ characteristics of DSSCs prepared using different ratios of clove fruit dye and acetic acid. (a) 3:1 (b) 2:1 (c) 1:1 (d) 1:2 (e) 1:3 (f) 1:4 (g) 1:5

Figure 04. (II) shows the current density (J) and voltage (V) characteristics of DSSCs fabricated using $\mathrm{TiO}_{2}$ photoanodes coated with different dye samples which are mixed with different ratios of clove fruit dye extracted in ethanol and acetic acid. The highest short circuit photocurrent density which is $2.50 \mathrm{~mA} \mathrm{~cm}^{-2}$ was obtained from the DSSC which was fabricated by dye mixed with acetic acid with the ratio 1:3.

Considering the figure 01. (II) and 04(II), the DSSCs made up of dye and acetic mixtures which have high absorption, are responsible for higher short circuit photocurrent densities [3]. This could happen because photon-to-current efficiency depends on the light absorption of the dye and the interaction between the dye and the $\mathrm{TiO}_{2}$. Furthermore, hydroxyl groups 
facilitate the strong chelation between the dye skeleton andTiO $\mathrm{Surface}_{2}$ for efficient transfer of electron.

\subsection{EIS Characterization of DSSCs}
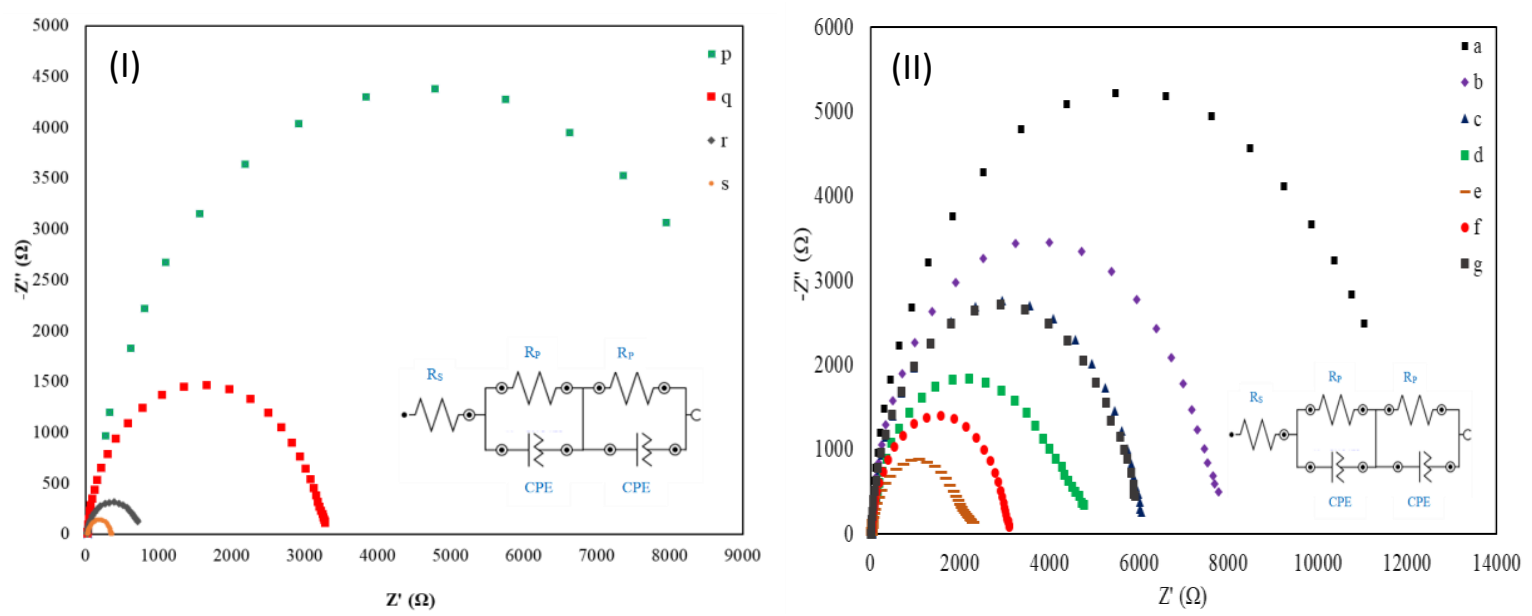

Figure 05: (I) Nyquist plot of DSSCs prepared using clove fruit dye with different solvents. (p) Distilled water (q) Distilled water $\left(100{ }^{\circ} \mathrm{C}\right)(\mathrm{r})$ Ethanol (s) Ethanol $\left(80{ }^{0} \mathrm{C}\right)$. (II) Nyquist plot of DSSCs prepared using different ratios of clove fruit dye and acetic acid. (a) 3:1 (b) 2:1 (c) $1: 1$ (d) $1: 2$ (e) 1:3 (f) 1:4 (g) 1:5. Inserts: Equivalent circuit for impedance spectra drawn by curve fitting.

Information on the kinetic process of electrochemical and photoelectrochemical processes taking place in the DSSCC is provided by electrochemical impedance measurements (EIS). Electron recombination resistant and effective electron lifetime could be determined by using an appropriate equivalent circuit model to represent the DSSC to fit the experimental EIS spectra.

Figure 05 shows electrochemical impedance spectra of the DSSCs prepared using clove fruit dye with different solvents. According to the results of the above curves, highest impedance is obtained for DSSC which was fabricated using extracted dye by boiling in ethanol at 80 ${ }^{0} \mathrm{C}$.

Figure 06(I) and (II) shows the bode plot of $\mathrm{TiO}_{2}$ /dye/electrolyte/Pt DSSCs for DSSCs prepared using clove fruit dye with different solvents. From the peak value in the bode phase plots corresponding to the characteristic angular frequency $\left(\omega_{\mathrm{mid}}\right)$ of the middle frequency $\left(f_{\text {mid }}\right)$, the electron lifetime in the conduction band can be determined [4]. Therefore, the lifetime of the electron $\left(\tau_{\mathrm{e}}\right)$ was determined using the following relationship, 


$$
\tau(e)=\frac{1}{\omega_{\text {mid }}}=\frac{1}{2 \pi f_{\text {mid }}}
$$
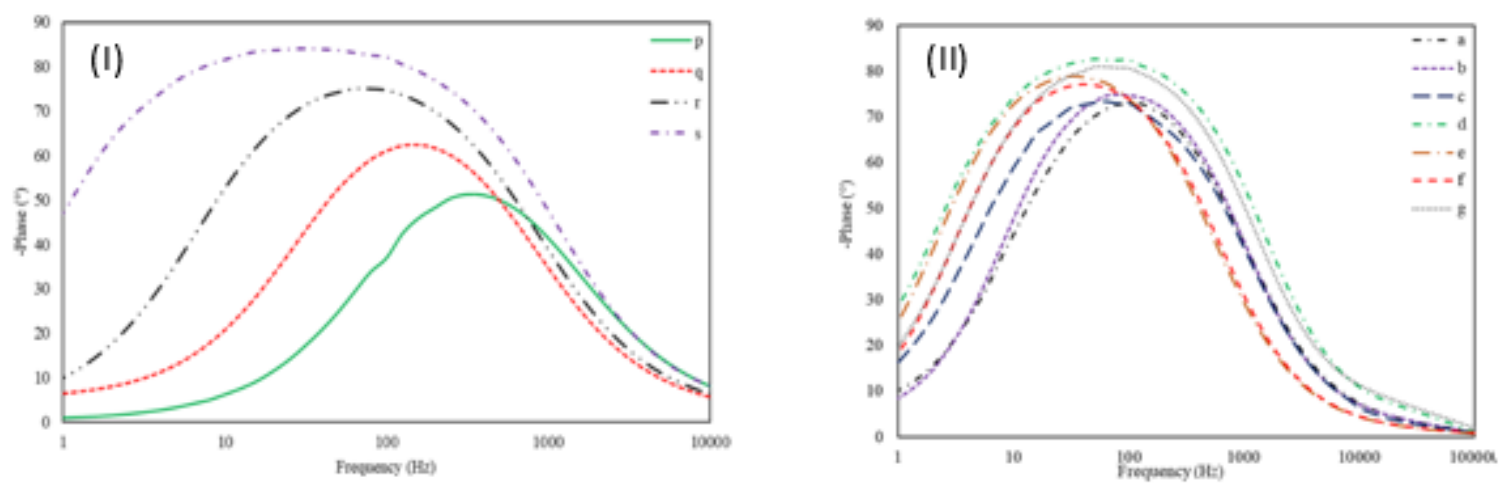

Figure 06: (I) Bode phase plot of DSSCs prepared using clove fruit dye in different solvents. (p) Distilled water (q) Distilled water $\left(100{ }^{0} \mathrm{C}\right)(\mathrm{r})$ Ethanol (s) Ethanol $\left(80{ }^{0} \mathrm{C}\right)$. (II) Bode phase plot of DSSCs prepared using different ratios of clove fruit dye and acetic acid. (a) 3:1 (b) $2: 1$ (c) $1: 1$ (d) $1: 2$ (e) $1: 3$ (f) $1: 4$ (g) $1: 5$

The electron lifetime in the conduction band calculated from the peak values of the middle frequency of the bode phase plots are given in table 01 and table 02 . According to table 01 electron lifetime of DSSCs fabricated using dye extracted to distilled water and boiled distilled water are relatively the same. But electron life time of two of them are relatively lower than dye samples which was extracted to ethanol. The dye layer is intended to function as a barrier between the semiconductor and the electrolyte in order to suppress electron recombination with a thicker dye layers to enhance the electron lifetime.

Table 01: Photovoltaic measurements and electron lifetimes of DSSCs of the configuration $\mathrm{TiO}_{2} /$ dye/electrolyte/Pt prepared using dye solutions of different solvents.

\begin{tabular}{|l|c|c|c|c|c|c|}
\hline \multicolumn{1}{|c|}{ solvent } & $\begin{array}{c}\mathrm{J}_{\mathrm{SC}} \\
\left(\mathrm{mA} \mathrm{cm}^{-2}\right)\end{array}$ & $\begin{array}{c}\mathrm{V}_{\mathrm{OC}} \\
(\mathrm{V})\end{array}$ & $\begin{array}{c}\mathrm{FF} \\
(\%)\end{array}$ & $\begin{array}{c}\eta \\
(\%)\end{array}$ & $\begin{array}{c}\text { Frequency } \\
(\mathrm{Hz})\end{array}$ & $\begin{array}{c}\text { life time } \\
(\mathrm{ms})\end{array}$ \\
\hline Distilled water & 0.31 & 0.273 & 33.09 & 0.03 & 316.23 & 0.543 \\
\hline water $\left(100^{0} \mathrm{C}\right)$ & 0.36 & 0.354 & 40.49 & 0.05 & 293.36 & 0.504 \\
\hline Ethanol & 0.49 & 0.391 & 47.76 & 0.09 & 158.43 & 1.005 \\
\hline Ethanol $\left(80^{0} \mathrm{C}\right)$ & 0.52 & 0.410 & 45.68 & 0.10 & 129.95 & 1.225 \\
\hline
\end{tabular}


Table 02: Photovoltaic measurements and electron lifetimes of DSSCs with the configuration $\mathrm{TiO}_{2} /$ dye/electrolyte/Pt prepared using different dye and acetic ratios.

\begin{tabular}{|c|c|c|c|c|c|c|}
\hline $\begin{array}{c}\text { Clove fruit dye } \\
\& \\
\text { acetic acid ratio }\end{array}$ & $\begin{array}{c}\mathrm{J}_{\mathrm{SC}} \\
\left(\mathrm{mA} \mathrm{cm}^{-2}\right)\end{array}$ & $\begin{array}{c}\mathrm{V}_{\mathrm{OC}} \\
(\mathrm{V})\end{array}$ & $\begin{array}{c}\mathrm{FF} \\
(\%)\end{array}$ & $\begin{array}{c}\eta \\
(\%)\end{array}$ & $\begin{array}{c}\text { Frequency } \\
(\mathrm{Hz})\end{array}$ & $\begin{array}{c}\text { life time } \\
(\mathrm{ms})\end{array}$ \\
\hline $3: 1$ & 0.52 & 0.521 & 35.95 & 0.10 & 125.89 & 1.2649 \\
\hline $2: 1$ & 0.23 & 0.410 & 56.41 & 0.20 & 79.433 & 2.0047 \\
\hline $1: 1$ & 0.73 & 0.444 & 56.57 & 0.33 & 63.096 & 2.5237 \\
\hline $1: 2$ & 1.27 & 0.457 & 45.57 & 0.40 & 50.119 & 3.1771 \\
\hline $1: 3$ & 2.50 & 0.449 & 61.57 & 0.69 & 31.623 & 5.0354 \\
\hline $1: 4$ & 1.14 & 0.438 & 57.48 & 0.44 & 39.811 & 3.9997 \\
\hline $1: 5$ & 0.68 & 0.410 & 51.94 & 0.17 & 63.096 & 2.5237 \\
\hline
\end{tabular}

The $\mathrm{pH}$ values of dye extracted to distilled water and ethanol are 4.86 and 6.15 respectively. Despite the low $\mathrm{pH}$ of dye extracted to water, dye extracted to ethanol readily adsorb on $\mathrm{TiO}_{2}$ because of the lower polarity of ethanol than water. The adsorption of the dye is strongly depended on the polarity of the solution. Therefore, the recombination of electrons in DSSC prepared using dye extracted to ethanol is lower than the dye extracted to distilled water due to better adsorption of the dye. As a result, electron life time is higher in the DSSC prepared by dye extracted in ethanol. Subsequently, alteration of the $\mathrm{pH}$ of the dye extracted to ethanol also stimulated the electron lifetime as evident from table 02 where the highest life time was recorded for 1:3 volume ratio of dye in ethanol to acetic acid.

\section{CONCLUSION}

A DSSC with the configuration, $\mathrm{TiO}_{2} /$ dye/electrolyte/Pt was fabricated using Clove fruit dye as the sensitizer. Photovoltaic performance was high when the extract was in ethanol than in water where the adsorption of the pigments is strongly determined by the polarity of the solvent. After acidification, the light absorption at $510-520 \mathrm{~nm}$ and $650-700 \mathrm{~nm}$ ranges in UV-visible spectra attributes to high current density and efficiency of those DSSCs. The most suitable ratio of clove fruit dye and acetic acid was found as 1:3 to obtain the highest efficiency of the DSSCs. The electron life time calculated from bode phase plots also supported the above observations. Acidic form of the dye intensifies the light absorption and also the functionalization of the dye with hydroxyl groups facilitate strong coupling of the dye with $\mathrm{TiO}_{2}$. Therefore, both the effects simultaneously contribute for these enhancements. 


\section{REFERENCES}

1. Grätzel, M., Dye-sensitized solar cells, Journal of Photochemistry and Photobiology C Photochemistry Reviews, 4(2), (2003) 145-153.

2. Ma, Y. N., Xu, F. R., Chen, C. J., Li, Q. Q., Wang, M. Z., Cheng, Y. X., \& Dong, X., The beneficial use of essential oils from buds and fruit of Syzygium aromaticum to combat pathogenic fungi of Panax notoginseng, Industrial Crops and Products, 133, (2019), 185-192.

3. Luoa. L.P., Niua. H., Zhenga. G., Bai. X., Zhang. M., Wangc. W., From salmon pink to blue natural sensitizers for solar cells: Canna indica L. Salvia splendens, cowberry and Solanum nigrum., Spectrochimica Acta Part A: Molecular and Biomolecular Spectroscopy 74, no. 4, (2009) 936-942

4. Wickramasinghe.G.C., Balasundaram, D., Rajasekara. U.G.M.D., Aponsu. G.M.L.P., Perera. V.P.S., Optimization of Adsorption of Carissa carandas Dye on TiO2 Photoanodes for Efficient Sensitization of DSSCs., Proceedings of the Technical Sessions of the Institute of Physics, Sri Lanka, session 35, (2019), 1-8. 